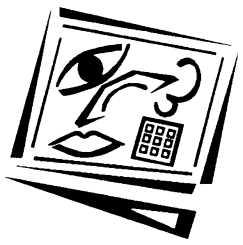

\title{
Gender differences in learning styles: Nurturing a gender and style sensitive computer science classroom
}

\author{
Wilfred Wing Fat Lau and Allan Hoi Kau Yuen \\ The University of Hong Kong
}

\begin{abstract}
The gender digital divide has been widely discussed and researched over the years. Previous studies have focused on a number of factors such as computer attitude, computer anxiety, computer self-efficacy, and computer experience. This study empirically tested the sensitivity of a learning style instrument, the Gregorc Style Delineator (GSD), to gender in a sample of students who studied computer programming in Hong Kong secondary schools. Results indicated that females had higher preference for concrete sequential (CS) and abstract random (AR) compared with males. Males had higher preference for concrete random (CR) than females. From these results, we proposed learning style-based pedagogical practices to teach computer programming. In order to address the needs of female students, we further proposed that learning style-based pedagogical practices need to move from a gender neutral to gender sensitive approach. This proposal helps to improve student learning through individualisation in pedagogy in terms of gender and learning styles and contributes to a gender and style sensitive computer science classroom. Eventually, through various remedial interventions, we anticipate more female participation in computer science field and hence the gender issue is addressed.
\end{abstract}

\section{Background}

In today's society, our younger generation has more access to a wide variety of information through various media. This situation is further augmented due to the advancement of information and communication technologies, in particular smartphones, laptops, and the Internet. While the media provides timely information and entertainment to us, its potential detriments cannot be underestimated. The term digital divide has been used to describe the phenomenon in which the poorer, less educated, and those from rural areas cannot participate equally in this information era (Cooper, 2006). Yet a gender digital divide has been permeating in our society that deserves our attention. Low participation of females in computer science field has been a long standing problem. According to a study by Ilias and Kordaki (2006), females are under-represented in all fields of computer science in academia and industry.

In the US, figures released by the National Center for Women \& Information Technology (NCWIT) reaffirm how severe this gender digital divide is (http:/ / www.ncwit.org/about.factsheet.html) [verified 11 Dec 2010]. For instance, in 2008, girls accounted for about 17 percent of the test-takers in the Advanced Placement Computer Science and only 18 percent of computer science and information sciences undergraduate degree recipients were female.

This is in fact a global issue. Statistics showed that female participation in computer science field ranged from $10 \%$ to $40 \%$ in most countries and courses (Galpin, 2002). The 
status-quo of gender imbalance in computer science field is pervasive. A number of explanatory factors have been highlighted throughout the literature such as computer attitude, computer anxiety, computer self-efficacy, and computer experience (Cassidy \& Eachus, 2002; Kadijevich, 2000; King, Bond \& Blandford, 2002). However, there is a lack of research that investigates the issue of gender differences in learning styles. Do computers or technologies favour certain styles that are averse to females? As Ames (2003) suggested, "identification of this gender difference (in learning styles) may provide an understanding of why females generally choose not to major in computer science or other technology-intensive field" (p. 240). We urge the need to look into this issue. In doing so, through various remedial interventions, it is our intent that increased female participation in computer science field is ensured and the gender issue is addressed.

This article reports an empirical study of the sensitivity of learning styles to gender in a sample of computer programming students in Hong Kong secondary schools and is structured as follows. First, studies on the factors for female under-representation in computer science are reviewed. Second, gender and learning styles are discussed. Then, gender differences in learning styles are examined. Next, the learning style instrument, the Gregorc Style Delineator (GSD), used in this study and its relationship with gender is described. This is followed by the method and results sections. In the discussion section, pedagogical implications are deliberated from the perspectives of gender neutral and gender sensitive approaches. Finally, a conclusion summarising the major findings in this study is provided.

\section{Factors for female under-representation in computer science field}

The issue of low participation of females in computer science has drawn much academic attention since the popularity of computers in the community developed. Admittedly, to understand fully the interplay of various factors in this phenomenon is no easy task at all. There are sociological, cultural, and psychological factors involved and all play a part in the issue. Over the years, research has demonstrated that the following factors contribute to the gender differences in computer literacy and participation: differential access to computer (Reinen \& Plomp, 1997), existence of gender-biased computer games (Goritz \& Medina, 2000), role models (Gürer \& Camp, 2002), gender stereotype (Spencer, Steele \& Quinn, 1999), computer attitude (Kadijevich, 2000), computer anxiety (King, Bond \& Blandford, 2002), and computer self-efficacy (Cassidy \& Eachus, 2002).

The extent to which students have access to computers is historically identified as a cause of the gender differences in computer uses in education. Based on the data sources from an international study, Reinen and Plomp (1997) found that in nearly all participating countries, males had more access to computers at home. Females had access only to school computers in many countries. The authors concluded that "socialization experiences and access to computers lead, at least in some countries, to the creation and/or preservation of gender differences." (p. 73). The computer game industry has been criticised for an inclination towards the boys and males market, as the majority of the games produced have tended to contain far more masculine than feminine features. Goritz and Medina (2000) argued that as most children had their first experience of using computers through software-based games and most of these games were targeted at boys, this resulted in negative stereotype to computers among girls. They noted that boys and girls had different interests concerning computer 
games. In general, boys had preferences for games that "fit into the categories of action, strategy, adventure, simulation, and sports" (p. 45), whereas girls preferred games that are more "creating than destroying" (p. 45). They claimed that by investing into the girls game market and playing computer games, girls might be encouraged "to pursue computer courses at early stages, and entice them to regard computer science as an attractive career choice." (p. 49). Role models are important figures through which novices can learn and imitate during their academic and career journey. Gürer and Camp (2002) suggested that role modelling was one way to increase female participation in computing. In practical terms, these can be established through interaction with "women computer scientists online, in person, or through biographies, public talks, or the history of computer science" (p. 122).

Gender stereotype is perhaps the most widely adopted reason for the gender digital divide. The computing academia and profession consist mainly of males and this male dominating effect is further exacerbated by the media, which intentionally or unintentionally portray the computing field as a masculine arena. A study by Spencer, Steele and Quinn (1999) confirmed the effect of gender-based stereotype threat. They found that men outperformed women on a difficult mathematics test but not an easy test. To remove the confounding effect of ability on performance differences, a second difficult test was administered to all the participants in the two conditions where one had gender differences (stereotype relevant) and the other did not (stereotype irrelevant). In the stereotype relevant condition, women still underperformed compared with men while in the stereotype irrevant condition, no significant gender differences in performance were observed.

Some evidence seems to suggest that males' attitude towards computers is more positive. Kadijevich (2000) demonstrated that males did have a more positive attitude towards computers than females even after controlling for the effect of computer experience or interest. The findings suggested that there possibly be other variables to explain the gender differences in computer attitude. Among all the reported factors affecting computer participation, computer anxiety is considered to be the most trivial one. It is accepted that the higher the anxiety, the lower the participation. However, the reality might be more complicated owing to the presence of other factors. In fact, King, Bond and Blandford (2002) found that when taking into account gender and grade, males had a slightly higher level of anxiety than females. Females had a higher anxiety level at grade 7, similar anxiety level at grade 9, but lower anxiety at grade 11 than males. The authors ascribed the lower anxiety level of females at grade 11 to the familiarity of computer usage as word processor and the use of computers as a communication tool and the higher anxiety level of older males to an association of computers with academic subjects as being 'uncool'.

Self-efficacy has been described as a critical element in accomplishing tasks successfully. In developing and validating a computer user self-efficacy (CUSE) scale, Cassidy and Eachus (2002) found that males had consistently higher self-efficacy than females irrespective of whether or not a computer training course had been attended before. Perceived masculinity of the task did not seem to explain the gender differences in computer self-efficacy. Experience with computers and familiarity with computer software packages were the two most important predictors of computer selfefficacy. In a literature review of research on the gender digital divide, Cooper (2006) argued that the digital divide can be boiled down to a problem of computer anxiety. She further proposed a causal model incorporating gender stereotype, attribution 
patterns, and stereotype threat as the predecessors of computer anxiety, and computer anxiety as a predecessor of computer attitude and computer performance.

\section{Gender and learning styles}

The preceding section presented a series of contextual factors influencing participation and performance of students in computer science. The intricacies of these factors further obscure a full understanding of the issue. However, in terms of learning styles, there is growing evidence to show that differences of learning styles in terms of gender are socially constructed in the science, maths, engineering, and technology (SMET) fields (Milgram, 2009). Hyde (2005) meta-analysed 46 gender-related studies and concluded that males and females are similar instead of different in most psychological variables including mathematics ability. In other words, the observed differences in most variables between males and females are not innate. Thus, the basic premise in our study is that if the gender digital divide is mainly due to nurture instead of nature, it is then imperative for educators to nurture a gender sensitive and in particular, female friendly, environment to engage more female participation. Nonetheless, not much effort has been made into investigating the possible effects of the gender differences in learning styles on teaching and learning computer programming. This study aims to examine the gender differences in learning styles of computer programming students.

\section{Gender differences in learning styles}

Using the Myers-Briggs Type Indicator, Nuby and Oxford (1996) found a significant difference in learning style preferences of secondary school students from the African American and Native American cultures. African American male and female students indicated a strong preference for the sensing and judging dimensions. On the other hand, Native American male and female students indicated a preference for the intuition and perception dimensions. Regardless of the populations concerned, female students indicated a much stronger preference for the feeling dimension. In a study conducted by Honigsfeld and Dunn (2003) to explore the gender differences in learning styles of adolescents among five nations, it was found that girls showed higher levels of self motivation, persistence, responsibility, need for warmer temperatures, sociological variety, parent motivation, and teacher motivation than boys, using the Dunn and Dunn's Learning Style Inventory. Wehrwein, Lujan and DiCarlo (2007) investigated gender differences in learning style preferences in a group of undergraduate physiology students using the VARK questionnaire. The questionnaire consists of items related to learning style preferences in visual (V: learning from graphs, charts, and flow diagrams), auditory (A: learning from speech), read-write (R: learning from reading and writing), and kinaesthetic (K: learning from touch, hearing, smell, taste, and sight). Results indicated that most male students preferred multimodal instruction, specifically, four modes (VARK), whereas most female students preferred single mode instruction, in particular, the K mode.

Severiens and Ten Dam (1994) performed a meta-analysis of the gender effect on two learning style instruments, namely Kolb's Learning Style Inventory and Entwistle's Approaches to Studying Inventory, and found a significant gender preference on subscales of these instruments. Men tended to prefer the abstract conceptualisation mode of learning more than women, according to Kolb's instrument. Men were likely to adopt a deep approach, be extrinsically motivated and achievement oriented, compared with women, according to Entwistle's instrument. Using Canfield's Learning 
Style Inventory, Keri (2002) found that more males showed a preference for applied learning styles in which they preferred using everyday life experience as a basis for learning, whereas females tended to be more abstract in that they opted for copious reading assignments, organised learning materials and instructors' knowledge, for learning. These results indicate that there are clear gender differences in learning styles regardless of the instruments used.

\section{The Gregorc Style Delineator}

The Gregorc Style Delineator (GSD) (Gregorc, 1982) was used to measure participants' learning styles in this study. According to Gregorc, the human mind has channels through which information is received and expressed most efficiently and effectively. Gregorc further introduced the term mediation abilities and defined the term style as the external appearance of an individual's mediation abilities. As there are two mediation abilities with two qualities, this results in the formation of four mediation channels of mind styles: concrete sequential (CS), abstract sequential (AS), concrete random (CR), and abstract random (AR). The typical style characteristics of the four dominant channels are shown in Table 1.

Table 1: Style comparison

\begin{tabular}{|l|l|}
\hline \multicolumn{1}{|c|}{ Learning style } & \multicolumn{1}{c|}{ Typical style characteristics } \\
\hline Concrete sequential (CS) & $\begin{array}{l}\text { CS learners tend to perceive reality through their physical senses } \\
\text { and think in an orderly, logical, and sequentially manner. }\end{array}$ \\
\hline Abstract sequential (AS) & $\begin{array}{l}\text { AS learners are logical and analytical individuals who have a } \\
\text { preference for mentally stimulating task and environment. }\end{array}$ \\
\hline Concrete random (CR) & $\begin{array}{l}\text { CR learners like to experiment with ideas and concepts and think } \\
\text { intuitively, instinctively, impulsively, and independently. }\end{array}$ \\
\hline Abstract random (AR) & $\begin{array}{l}\text { AR learners have a strong sense on the world of feeling and emotion } \\
\text { and tend to think in a non-linear and emotional manner. }\end{array}$ \\
\hline
\end{tabular}

The GSD was selected for use in this study due to the following reasons. First, many studies that employed the instrument have found consistent learning style differences between the sexes (Ames, 2003; Gentry \& Helgesen, 1999; Gould \& Caswell, 2006; Myers \& Dyer, 2006; O'Brien, 1994; Orr, Park, Thompson \& Thompson, 1999; Ross, 1997). In general, males tend to be CS/CR learners whereas females tend to be AR learners. Second, previous research has shown the effects of learning styles on academic performance in computer applications courses with some component of computer programming (Davidson, Savenye \& Orr, 1992; Drysdale, Ross \& Schulz, 2001; Ross, Drysdale \& Schulz, 2001). Sequential learners generally outperform random learners in programming courses.

The scores in the GSD are obtained by ranking four words at a time from 1 to 4 with 4 given to most suitable description of oneself and 1 given to the least suitable one. Each word in a four-word group belongs to one of the four channels. Ten such groups then determine the total scores in the four mediation channels by summing the scores in each channel of the groups. Since there are four words in each of the ten groups and the words are ranked from 1 to 4 , the scores in each channel can range from 10 to 40 . Scores from 27 to 40 indicate a strong orientation towards that learning style whereas scores from 10 to 15 indicate a weak orientation towards that learning style. The highest score among the four channels determines the dominant learning style and the lowest score determines the weakest learning style. In practice, a combination of types is likely to emerge. 


\section{Gender and the Gregorc Style Delineator}

Learning style preferences based on gender using the GSD have been welldocumented in the literature. O'Brien (1994) found that although AR students accounted for $40 \%$ of a sample of high school students, males were predominantly CR whereas females were predominantly AR. He further concluded that "males were far more concrete $(n=99,57 \%)$, while females were far more abstract $(n=147,60 \%)^{\prime \prime}$ (p. 18). Ames (2003) showed that a significant gender difference in the AR subscale existed and females were more likely to be AR than males. Orr et al. (1999) demonstrated that males tended to be AS and CR while females tended to be AR in a group of postsecondary students in vocational technical institutes. Gould and Caswell (2006) found that male undergraduate athletic training students had a higher preference for AS compared with their female counterparts. Conversely, female undergraduate athletic training students had a higher preference for AR compared with their male counterparts. Gentry and Helgesen (1999) showed that in a group of undergraduate financial management students, there were significantly more women with AR and CS styles than men. Men, on the other hand, were more numerous in AS and CR styles than women.

Ross (1997) found that there were more sequential learners (53.9\%) among males, whereas there were more random learners $(54.5 \%)$ among females in a sample of university students. Myers and Dyer (2006) observed that male agricultural university students were CS learners (72.4\%) followed by AS learners $(41.1 \%)$, while for the female counterparts, CS learners were the largest group (62.2\%) followed by AR learners $(47.6 \%)$. It should be noted that in their study, some participants were classified into more than one category so that the sum of the percentages was greater than 100. These results show that males are predominantly CS or CR learners whereas females are predominantly AR learners. However, this study is different from the aforementioned studies in at least three ways. First, the purposes of the previous studies did not include examining gender differences in learning styles with the aim of promoting gender balance in education. Second, the domains of their research did not include computer science. Third, most studies selected postsecondary or university students as their subjects. In view of these distinct differences, there seemed to be good justification for conducting the present study.

\section{Method}

\section{Participants}

The participants in this study (121 females and 169 males) were two hundred and ninety Secondary 4 (Grade 10) or Secondary 5 (Grade 11) students who opted for the elective module A (Algorithm and Programming) in the computer and information technology curriculum from nine secondary schools in Hong Kong (the curriculum was replaced by a new one named information and communication technology starting from September 2009). They took part in this study on a voluntary basis through an invitation by their teachers. A substantial number of the participants $(80.3 \%)$ were between the ages of 14 to 16 . The mean age of females was 16.20 (SD = $0.85)$ while the mean age of males was $15.86(\mathrm{SD}=0.78)$. 


\section{Instrument}

In terms of reliability, Gregorc (1984) reported a standard alpha from 0.83 to 0.93 . Other researchers, Joniak and Isaksen (1988) and O'Brien (1990), found that the alpha coefficients were lower than the coefficients originally reported by Gregorc. Nevertheless, O'Brien argued that the items in the GSD jointly "have provided adequate measurement scales for the four constructs" (O'Brien, 1990, p. 635). Some studies also provide support for the use of the GSD in academic settings. For instance, Seidel and England (1997) concluded that "the reliability of the Gregorc learning styles delineator is sufficient to investigate the construct validity in terms of its use in the classroom" (pp. 10-11) and Butler and Pinto-Zipp (2005) also concluded "the strength of the GSD outweighs the weakness and the literature supports the use of the GSD in learning styles research" (p. 202). The occurrence of lower reliability could be due to differences in the sample, individuals being influenced by problems like mood, illness, or stress, and the ipsative scoring method of the instrument (Reio \& Wiswell, 2006; Ross et al., 2001).

\section{Procedure}

Data were collected through an online website. First, the participants were required to fill in some demographic information. Then the participants were asked to complete the self-reported GSD which took about 4 minutes. Before they actually did this, they were reminded that it was very important that they were to judge the relative value of the words in each group using the real self as the reference point, not the one at home or work. Also, they must rank the words in a group with their first impression.

\section{Results}

\section{Distribution of learning styles by gender}

In terms of dominant learning style, CS was the major style for females $(34.7 \%)$ followed by AR $(30.6 \%)$ while the major style for males was CR $(38.5 \%)$ followed by CS $(29.0 \%$ ) (see Table 2). Two participants (one male and one female) were identified as BI which indicates that their scores in the GSD were equal in two or more scales and could not be resolved $(\mathrm{CS}=25, \mathrm{AS}=25, \mathrm{AR}=25, \mathrm{CR}=25$ and $\mathrm{CS}=26, \mathrm{AS}=24, \mathrm{AR}=26$, $\mathrm{CR}=24)$. For the other cases, if the same scores occurred in two scales, style was assigned by considering the scores in other scales. For instance, if an individual obtained the scores $C S=21, A S=27, A R=27$ and $C R=25$, he or she was classified as an AR learner since the CR score was higher than the CS score.

Table 2: Distribution of dominant learning style by gender

\begin{tabular}{|l|l|c|c|c|c|c|c|}
\hline \multirow{2}{*}{} & \multicolumn{9}{|c|}{ Style } & \multirow{2}{*}{ Total } \\
\cline { 3 - 8 } & & AR & AS & BI & CR & CS & \\
\hline \multirow{3}{*}{ Female } & Frequency & 37 & 25 & 1 & 16 & 42 & 121 \\
\cline { 2 - 8 } & Row percentage & $30.6 \%$ & $20.7 \%$ & $0.8 \%$ & $13.2 \%$ & $34.7 \%$ & $100.0 \%$ \\
\cline { 2 - 8 } & Column percentage & $57.8 \%$ & $48.1 \%$ & $50.0 \%$ & $19.8 \%$ & $46.2 \%$ & $41.7 \%$ \\
\hline \multirow{3}{*}{ Male } & Frequency & 27 & 27 & 1 & 65 & 49 & 169 \\
\cline { 2 - 8 } & Row percentage & $16.0 \%$ & $16.0 \%$ & $0.6 \%$ & $38.5 \%$ & $29.0 \%$ & $100.0 \%$ \\
\cline { 2 - 8 } & Column percentage & $42.2 \%$ & $51.9 \%$ & $50.0 \%$ & $80.2 \%$ & $53.8 \%$ & $58.3 \%$ \\
\hline \multirow{2}{*}{ Total } & Frequency & 64 & 52 & 2 & 81 & 91 & 290 \\
\cline { 2 - 8 } & Overall percentage & $22.1 \%$ & $17.9 \%$ & $0.7 \%$ & $27.9 \%$ & $31.4 \%$ & $100.0 \%$ \\
\hline
\end{tabular}




\section{Association of gender and dominant learning style}

This hypothesis tested whether there was any association between gender and dominant learning style. The null hypothesis stated that there was no association between gender and dominant learning style. A single chi-square goodness of fit test was performed for the categorical variables gender and dominant learning style. A one-way MANOVA was also performed on the four dependent variables CS, AS, CR, and AR using gender as the independent variable. The two participants identified as BI (Table 2) in their learning styles were excluded from this analysis. Utilising the chisquare criterion, it was found that there was a gender effect on the dominant learning style, chi-square $(3)=24.5, \mathrm{p}<.001$. Utilising Wilks' lambda criterion, the combined dependent variables was affected by gender, $\mathrm{F}(3,284)=10.397, \mathrm{p}<.001$, partial etasquared $=0.099$. Therefore, the null for this hypothesis was rejected.

Univariate analyses were performed on the main effect of gender on each individual dependent variable (see Table 3 ). Results revealed that gender differences existed in $\mathrm{CS}, \mathrm{F}(1,286)=4.864, \mathrm{p}<.05$, partial eta-squared $=0.017, \mathrm{CR}, \mathrm{F}(1,286)=19.196, \mathrm{p}<.001$, partial eta-squared $=0.063$, and $\mathrm{AR}, \mathrm{F}(1,286)=9.371, \mathrm{p}<.01$, partial eta-squared $=$ 0.032 but not in AS, $\mathrm{F}(1,286)=0.083, \mathrm{p}=.774$. From Table 4 , females had higher preference for CS and AR compared with males. On the other hand, males had higher preference for CR than females.

Table 3: Analysis of variance for the gender differences in the GSD subscales

\begin{tabular}{|c|c|c|c|c|c|}
\hline & Subscale & df & $\mathrm{F}$ & $\begin{array}{l}\text { Partial eta- } \\
\text { squared }\end{array}$ & $\mathrm{p}$ \\
\hline Concrete & Between groups & 1 & 4.864 & 0.017 & $0.028^{*}$ \\
\hline sequential & Within groups & 286 & & & \\
\hline & Total & 287 & & & \\
\hline Abstract & Between groups & 1 & 0.083 & 0.000 & 0.774 \\
\hline sequential & Within groups & 286 & & & \\
\hline & Total & 287 & & & \\
\hline Concrete & Between groups & 1 & 19.196 & 0.063 & $0.001^{* * *}$ \\
\hline random & Within groups & 286 & & & \\
\hline & Total & 287 & & & \\
\hline Abstract & Between groups & 1 & 9.371 & 0.032 & $0.002^{* *}$ \\
\hline random & Within groups & 286 & & & \\
\hline & Total & 287 & & & \\
\hline
\end{tabular}

Table 4: Means and standard deviations of the GSD subscale scores by gender

\begin{tabular}{|l|l|c|c|c|}
\hline \multicolumn{1}{|c|}{ Subscale } & \multicolumn{1}{|c|}{ Gender } & $\mathrm{n}$ & Mean & SD \\
\hline \multirow{2}{*}{$\begin{array}{l}\text { Concrete } \\
\text { sequential }\end{array}$} & Female & 42 & 25.77 & 5.60 \\
\cline { 2 - 5 } $\begin{array}{l}\text { Abstract } \\
\text { sequential }\end{array}$ & Male & 49 & 24.25 & 5.86 \\
\cline { 2 - 5 } $\begin{array}{l}\text { Concrete } \\
\text { random }\end{array}$ & Male & 25 & 24.66 & 4.16 \\
\hline $\begin{array}{l}\text { Abstract } \\
\text { random }\end{array}$ & Memale & 16 & 24.80 & 3.98 \\
\cline { 2 - 5 } & Female & 65 & 23.67 & 5.26 \\
\cline { 2 - 5 } & Male & 27 & 25.90 & 5.84 \\
\hline
\end{tabular}




\section{Discussion}

It was found that females had higher preference for CS and AR compared with males. On the other hand, males had higher preference for CR than females. A relatively high proportion of AR learners among females was observed. Proponents of learning style research argue that differences in learning styles could be a vehicle to address learner differences and hence provide a viable way to individualise instruction to improve teaching and learning. Whereas some studies have produced promising results in support of their hypotheses, practical strategies as to how pedagody can be tailormade are inadequate.

\section{Learning styles and pedagogical practices}

It has been argued that learning style-based instruction is necessary to accommodate the needs of different learners. It remains a challenge as to how educators can translate learning style theory into practice to bring about pedagogical innovations. For example, Terry (2002) recommended the applications of the GSD theory in the four classroom learning contexts: teacher-led classroom presentations, student group discussions and projects, independent assignments, and testing situations. In view of these suggestions, the following practices can be implemented in a programming class taking into account differences in learning styles. In a teacher-led classroom presentations, which are mainly lecture-based, teachers may present materials in a logical manner with more detail to CS students. Active demonstrations or even giving opportunities to try out are also appealing to them. AS students would prefer a logically ordered lecture and presentations that reflect a teacher's expertise in the area concerned. Short lectures followed by question and answer periods and group discussions are favourable to AR learners. Movies and television shows are also effective to them. CR students do not like presentations with a lot of detail. Instead, they like to discover answers on their own and prefer a trial and error approach to explore alternatives. In practice, teachers may vary their presentations so that they are sometimes structured with detail and examples and sometimes less so. This not only appeals to both sequential and random students alternatively but also "give all learners opportunities to develop tolerance for both presentation styles" (p. 166).

In a setting of group discussions and projects, CS students like group discussions to be orderly, purposeful, and relatively quiet. They have the ability to keep the group on task and yet they would prefer to complete assigned work independently. AS students would prefer to discuss intellectually with teachers instead of fellow students and dislike group project work altogether. They could make valuable contributions to group project although other members may think they are too critical. AR students are fond of group discussions and projects. They bring affective qualities to a group and focus more on building relationships with others. CR students would also prefer group discussions and projects. They enjoy games and simulations in classrooms and are good group project leaders. The value of discussion classes is also supported by other computer science educators (Hagan \& Sheard, 1998). One way to balance between the needs of sequential and random learners, as suggested by Terry (2002), is to establish a "quiet corner" in a classroom separated by some visual barrier. This caters to the need of sequential learners for a less noisy environment and yet provides space for more interactions among random learners. 
Regarding individual assignments, CS students are highly organised and independent workers. They like lab assignments, workbooks, computerised instruction, and handson work. They would prefer precise and detailed instruction for completing assignment. To a certain extent, AS students are similar to CS students as independent learners. Yet they prefer to engage in research work, writing reports, and abstract learning tasks. Hands-on learning is not their favourite. AR students also prefer independent study projects. However, they appreciate substantive freedom and problem solving and abstract learning tasks in active and unstructured settings. They have difficulty in working with computers. CR students enjoy working in experimental, independent, and creative learning environments that nurture their exploration. They rely on the high standards set by their self competition drives to assess their learning outcomes. The implications of these are that instead of giving different assignments to different students, variations in terms of directions, deadlines, study topics, formats, nature of tasks, and working environments could be considered to match and mismatch learner preferences.

In testing situations, CS students prefer tests that require concrete and objective answers based on detailed information. They prefer testing environments which are quiet and uninterrupted. AS students prefer testing similar to that of CS students. They would prefer to develop their own strategies for taking tests. They like long answer test questions that require their ability to analyse information. AR students find it stressful to work alone in a traditional testing situation. They would rather be tested orally or based on classroom presentations. They prefer short essay questions instead of objective items. They perform best on questions that need interpretation rather than synthesis or analysis. CR students would rather be evaluated using takehome writing assignments and product-oriented projects. They would prefer open ended and problem solving questions that ask for their inquiry and investigation. These imply that, as a teacher, during the course of study, tests should be designed in a variety of formats including objective questions, short answer questions, long answer questions, and open ended questions in order to match and mismatch different learning styles of students.

\section{Pedagogical implications of gender differences in learning styles}

This study shows that females are more likely to be CS or AR learners compared with their male counterparts. On the other hand, males are more likely to be CR or CS learners. To compare the perception dimension of the GSD, the AS and AR categories were combined to estimate the abstract dimension and the CR and CS categories were combined to estimate the concrete dimension. Using this strategy, males were tended to be more concrete $(67.5 \%)$ while females were tended to be more abstract $(51.3 \%)$. These patterns mirror the findings on a sample of high school students by O'Brien (1994) and yet are different from the prediction on style distributions made by Gregorc (1984). One possible explanation is that adults were used in the study conducted by Gregorc (1984). Another possible explanation of this, as suggested by O'Brien (1994), is that learning styles may be a developmental process and its development becomes mature towards adulthood.

The pedagogical practices described in the previous section are meant to provide computer science educators with some practical strategies to address the issue of learning styles in teaching and learning computer programming. However, in order to cater to the females' needs, we argue that learning style-based pedagogical practices in 
teaching computer programming need to move from a gender neutral to gender sensitive approach. It has been reported in the literature that random learners, in particular AR learners, are potentially at a disadvantage when it comes to learning to program (Davidson et al., 1992; Drysdale et al., 2001; Ross et al., 2001). The poor performance of AR learners could be explained partly by the nature of learning to program. Learning to program inevitably involves the use of computers. However, there is some research evidence to suggest that computer-based instruction is inappropriate to AR learners and induces anxiety to them. Ames (2003) found that higher AR scores were associated negatively with confidence in using computers, and higher CR scores were associated negatively with computer affinity. She remarked that "for females with an Abstract Random style, computer facilitated instruction may not only be unwelcome but also be ineffective no matter how talented the instructor or how motivated the student" (p. 240). She further claimed that by reducing computer anxiety and increasing computer affinity and confidence, more females will be involved in technology based fields. Ross and Schulz (1999) also demonstrated that AR participants showed less interest in completing many computer based tasks compared with learners having the other three learning styles dominant.

In this information technologies era, many teachers are increasingly using computers to assist instruction without realising that computer-based instruction may be detrimental to certain styles of learning. In the context of learning computer programming, to cater to the learning needs of students, in particular the female AR students, the following recommendations made by Ross and Schulz (1999) are noteworthy. First, teachers should solicit the views of students on computer-based instruction and attempt to match their learning styles with instruction. Second, AR students should be given the opportunity to work with others to shift their attention away from machine to people in order to reduce the intimidating effect of computers. In fact, the idea of learning computer science with the minimal use of computers has been advocated and evaluated.

Three revelant programming pedagogies are suggested here to help to engage AR girls actively in computer science. The Computer Science Unplugged (Bell, Bensemann, \& Witten, 1995) is an initiative to help students to learn computer science concepts without using computers through hands-on activities. Another method is to use LEGO bricks to introduce programming and other computing concepts to students (Hood \& Hood, 2005). As AR learners prefer to work in groups, the idea of pair programming (Williams, Wiebe, Yang, Ferzli \& Miller, 2002) can be considered. In pair programming, two students work together to complete a program. In order to help AR learners, there should be a learner who is good at programming in a group. Preliminary evaluation supported the efficacy of the above innovations. Third, the initiative of converting traditional paper-based learning materials into an electronic version should be balanced against its potential problems such as ignoring learners preferring other styles. Specifically, the widespread use of e-learning systems should be considered carefully. While we aknowledge that long-term avoidance of using computers for programming activities is impractical, the above strategies are intended to help to create a more female friendly environment for students during an introductory phase and provide some alternative pedagogies during the learning phase. In short, diversified strategies of instruction should be adopted by teachers to accommodate at-risk learners, in particular those students who are impeded by computer-assisted learning. 
This study is not without its limitations. First, the structure of the GSD limits the number of questions and the variety of responses available to the participants. In future, it is desirable to conduct some in depth interviews with students to understand how and why they behave in learning to program. Second, contextual knowledge about the circumstances such as the nature of the curriculum as well as the pedagogy is central to student learning, and it should be considered in future studies. Third, as the sample in this study consisted of those females who have already chosen computer programming as a subject, more research is needed to investigate the vast majority of females who do not choose this subject.

\section{Conclusions}

This study shows empirically that learning styles, as measured by the GSD, are sensitive to gender in a sample of computer programming students in Hong Kong secondary schools. Results indicated that females had higher preference for CS and AR compared with their male counterparts. On the other hand, males had higher preference for $\mathrm{CR}$ than their female counterparts. Pedagogical implications of gender differences in learning styles are discussed. As computer science is still a young and emerging discipline, it is anticipated that workforce in the field is always in high demand. Low participation of females and high attrition of students are currently serious threats to the development of related industries. As Cooper (2006) contended, "Everyday, we risk losing the talents of women as contributors to science, technology, and the arts because the advantages that technology provide are being conveyed disproportionately to men in modern society" (p. 320). This research advances our understanding of the issue and suggests some partial remedies to alleviate the problem. Although further studies are required to validate our proposal, it serves as a research manifesto for computer science educators who are seriously thinking of implementing innovative pedagogical practices to narrow the gender gap. Through various remedial interventions, we anticipate more female participation in computer science field and hence the gender issue is addressed.

\section{References}

Ames, P. C. (2003). Gender and learning style interactions in students' computer attitudes. Journal of Educational Computing Research, 28(3), 231-244.

Bell, T. C., Bensemann, G. \& Witten, I. H. (1995). Computer science unplugged: Capturing the interest of the uninterested. Paper presented at the New Zealand Computer Conference, Wellington, New Zealand.

Butler, T. J. \& Pinto-Zipp, G. (2005). Students' learning styles and their preferences for online instructional methods. Journal of Educational Technology Systems, 34(2), 199-221.

Cassidy, S. \& Eachus, P. (2002). Developing the computer user self-efficacy (CUSE) scale: Investigating the relationship between computer self-efficacy, gender and experience with computers. Journal of Educational Computing Research, 26(2), 133-153.

Cooper, J. (2006). The digital divide: The special case of gender. Journal of Computer Assisted Learning, 22(5), 320-334.

Davidson, G. V., Savenye, W. C. \& Orr, K. B. (1992). How do learning styles relate to performance in a computer applications course? Journal of Research on Computing in Education, 24(3), 348-358. 
Drysdale, M. T. B., Ross, J. L. \& Schulz, R. A. (2001). Cognitive learning styles and academic performance in 19 first-year university courses: Successful students versus students at risk. Journal of Education for Students Placed at Risk, 6(3), 271-289.

Gürer, D. \& Camp, T. (2002). An ACM-W literature review on women in computing. SIGCSE Bulletin, 34(2), 121-127.

Galpin, V. (2002). Women in computing around the world. SIGCSE Bulletin, 34(2), 94-100.

Gentry, J. A. \& Helgesen, M. G. (1999). Using learning style information to improve the core financial management course. Financial Management $\mathcal{E}$ Education, 9, 59-69.

Goritz, C. \& Medina, C. (2000). Engaging girls with computers through software games. Communications of ACM, 43(1), 42-49.

Gould, T. E. \& Caswell, S. V. (2006). Stylistic learning differences between undergraduate athletic training students and educators: Gregorc mind styles. Journal of Athletic Training, 41(1), 109-116.

Gregorc, A. F. (1982). An adults guide to style. Columbia, CT: Gregorc Associates, Inc.

Gregorc, A. F. (1984). Gregorc Style Delineator: Development, technical and administration manual. Columbia, CT: Gregorc Associates, Inc.

Hagan, D. \& Sheard, J. (1998). The value of discussion classes for teaching introductory programming. SIGCSE Bulletin, 30(3), 108-111.

Honigsfeld, A. \& Dunn, R. (2003). High school male and female learning-style similarities and differences in diverse nations. The Journal of Educational Research, 96(4), 195-206.

Hood, C. S. \& Hood, D. J. (2005). Teaching programming and language concepts using LEGOs. SIGCSE Bulletin, 37(3), 19-23.

Hyde, J. S. (2005). The gender similarities hypothesis. American Psychologist, 60(6), 581-592.

Ilias, A. \& Kordaki, M. (2006). Undergraduate studies in computer science and engineering: Gender issues. SIGCSE Bulletin, 38(2), 81-85.

Joniak, A. J. \& Isaksen, S. G. (1988). The Gregorc Style Delineator: Internal consistency and its relationship to Kirton's Adaptive-Innovative distinction. Educational and Psychological Measurement, 48, 1043-1049.

Kadijevich, D. (2000). Gender differences in computer attitude among ninth-grade students. Journal of Educational Computing Research, 22(2), 145-154.

Keri, G. (2002). Male and female college students' learning styles differ: An opportunity for instructional diversification. College Student Journal, 36(3), 433-442.

King, J., Bond, T. \& Blandford, S. (2002). An investigation of computer anxiety by gender and grade. Computers in Human Behavior, 18(1), 69-84.

Milgram, D. (2009). Gender differences in learning style specific to science, math, engineering and technology (SMET). [verified 11 Dec 2010] http:/ / www.selfgrowth.com/articles/Gender_Differences_in_Learning_Style_Specific_to_S cience_Technology_Engineering_and_Math_ST̄EM.html

Myers, B. E. \& Dyer, J. E. (2006). The influence of student learning style on critical thinking skills. Journal of Agricultural Education, 47(1), 43-52.

Nuby, J. F. \& Oxford, R. L. (1996). Learning style preferences of native American and AfricanAmerican secondary students as measured by the MBTI. Paper presented at the Annual Meeting of the Mid-South Educational Research Association, Tuscaloosa, AL, USA.

O'Brien, T. P. (1990). Construct validation of the Gregorc Style Delineator: An application of LISREL 7. Educational and Psychological Measurement, 50, 631-636. 
O'Brien, T. P. (1994). Cognitive learning styles and academic achievement in secondary education. Journal of Research and Development in Education, 28(1), 11-21.

Orr, B., Park, O., Thompson, D. \& Thompson, C. (1999). Learning styles of postsecondary students enrolled in vocational technical institutes. Journal of Industrial Teacher Education, $36(4), 5-20$.

Reinen, I. J. \& Plomp, T. (1997). Information technology and gender equality: A contradiction in terminis? Computers $\mathcal{E}$ Education, 28(2), 65-78.

Reio, T. G. \& Wiswell, A. K. (2006). An examination of the factor structure and construct validity of the Gregorc Style Delineator. Educational and Psychological Measurement, 66(3), 489-501.

Ross, J. \& Schulz, R. (1999). Can computer-aided instruction accommodate all learners equally? British Journal of Educational Technology, 30(1), 5-24.

Ross, J. L. (1997). The effects of cognitive learning styles on human-computer interaction: Implications for computer-aided learning. Unpublished Masters thesis, The University of Calgary, Alberta, Canada.

Ross, J. L., Drysdale, M. T. B. \& Schulz, R. A. (2001). Cognitive learning styles and academic performance in two postsecondary computer a pplication courses. Journal of Research on Computing in Education, 33(4), 400-412.

Seidel, L. \& England, E. M. (1997). Gregorc's cognitive styles: Preferences for instructional and assessment techniques in college students. Paper presented at the Annual Convention of the American Psychological Association, Washington, DC, USA.

Severiens, S. E. \& Ten Dam, G. T. M. (1994). Gender differences in learning styles: A narrative review and quantitative meta-analysis. Higher Education, 27(4), 487-501.

Spencer, S. J., Steele, C. M. \& Quinn, D. M. (1999). Stereotype threat and women's math performance. Journal of Experimental Social Psychology, 35(1), 4-28.

Terry, M. (2002). Translating learning style theory into developmental education practice: An article based on Gregorc's cognitive learning styles. Journal of College Reading and Learning, 32(2), 154-176.

Wehrwein, E. A., Lujan, H. L. \& Di Carlo, S. E. (2007). Gender differences in learning style preferences among undergraduate physiology students. Advances in Physiology Education, 31, 153-157.

Williams, L., Wiebe, E., Yang, K., Ferzli, M. \& Miller, C. (2002). In support of pair programming in the introductory computer science course. Computer Science Education, 12(3), 197-212.

Dr Wilfred Wing Fat Lau (corresponding author), Honorary Research Associate, The University of Hong Kong, Faculty of Education, Pokfulam, Hong Kong SAR.

Email: wilfredlau@graduate.hku.hk

Dr Allan Hoi Kau Yuen, Associate Professor, The University of Hong Kong, Faculty of Education, Pokfulam, Hong Kong SAR.

Email: hkyuen@hkucc.hku.hk Web: http: / / people.cite.hku.hk/hkyuen 